\title{
Aspects of using and producing information resources: EUSIDIC Annual Conference 2006
}

\author{
9-11 April 2006, Innsbruck, Austria
}

In spite of the nearness of Easter and various difficulties met by EUSIDIC last year, the seminar was successful: the presentations were informative, the audience attentive and the conversations lively - and if the concentration lapsed for a moment, the Alps offered a soothing view behind the windows of the conference hall.

This was the fourth time that the EUSIDIC Conference was held in Austria, the first time having been 30 years ago (1976) in Graz, which many participants were reminiscing with nostalgic smiles.

The theme of the seminar was "Integration versus granularity of information resources - Interoperability and interconnectivity of services, systems and media manifestations".

These somewhat misty terms got more meaning in the presentations, which handled e.g. databanks, eLib consortia and electronic archiving/institutional repositories.

The occasion was opened by Manfred Gantner, the Chancellor of the University of Innsbruck, who emphasised the significance and mission of EUSIDIC.

The first key note lecture was self-evidently given by Dr. Heinz Hauffe from Innsbruck University Library. To honour his long and prolific career in the library profession and his contributions to EUSIDIC, all future conferences will include a special lecture on his name.

\section{Open Access not the only solution for the serials crisis}

For years one topical issue for all research libraries has been the journal price crises. Hauffe pointed out that if the number of players in the scientific information market is reduced, the costs will go down significantly. Approving nods from the audience, including from the publishing industry.

Hauffe also thought that the impact factor counting of journals should be replaced by judgments of articles themselves. The Open Access system was in his opinion not the only nor the best solution for the serials crisis - and in any case OA should provide fewer declarations and more action.

OA got critical comments from the audience, too. Instead of publishing activity OA could or should be seen just as giving access to documents. Also, when comparing publishing companies - often considered the greedy rogues in the world of publishing - with scientific societies we notice that they both want money for their publications. Moreover, as authors or their institutions have to pay to get their work published in the OA system, the same money could as well be given to some market system solution. 
But everything is going digital

The time of collection consistency policy is over: libraries (and enterprises) buy what they need "justin-time" instead of "just-in-case". This is possible because serials and their delivery have gone digital.

Helmut Hartman (Austrian Consortia Cooperation) reminded us that even though publishers sell their e-journals in ready-made packages they have carefully counted that it is cheaper for research libraries to buy their most important journals (or article databases) in a consortium. A centralized administration of subscriptions and joint cataloguing save costs, and even small libraries have the advantage of getting access to journals that otherwise would be far too expensive for them. However, to be more than just a buying club a consortium must have at least committed membership, strong leadership, clear ownership relations and adequate staffing.

\section{New material not necessarily available in databases}

Sleep was wiped from any sleepy eyes on the second morning of the Conference, when Evelyn Pipp (Innsbruck University Library) started to tell us about the shocking findings she had made in the article databases.

As the publishing industry does not want to lose the subscriptions of hard copy journals, the article content in the corresponding databases is available with an embargo of e.g. 6 months or even a year.

When scrutinising the databases Pipp and her colleagues had noticed that the content coverage changed every year and that there were more and more restrictions and embargoes. The database subscriptions (i.e. contracts) are renewed yearly, but the publishers/owners do not tell about the changes in the journal portfolio.

In addition to the delay of publishing the electronic texts, also archiving constitutes a burning issue. If the database contract forbids archiving, the library is forced to renew the subscription eternally to ensure the access to older material.

One journal may be available in several databases; some owners/publishers might offer it without embargoes and with archiving rights, but these agreements are often beyond the financial possibilities of a library. Article databases are, however, so useful for students and researchers that a thought of cutting off the subscription is unrealistic.

\section{Copyright issues of institutional repositories}

Another kind of archiving problem was treated by Pekka Olsbo, who is in charge of the management of electronic publications in the university of Jyväskylä (Finland). In his opinion, saving the publications of the organisation involves four aspects: identification data (of the author), the metadata (of the publication), agreement of later use (copyright contract) and the handling of the material itself. When all this has been seen to, everything is in order.

Of the 55 Nordic libraries who had answered a questionnaire concerning institutional repositories, all either had it already or were planning to build one. Only 17, however, acquired intellectual property rights for the material systematically and not more than two had a system to carry it out electronically while submitting the material.

Today distributing, copying and saving electronic material is so easy that authors and savers do not always think about those who in 10 or 30 years need to know what conditions the author has set for the re-use of his material. 
One problem of establishing institutional repositories is defining what should be included, i.e. what is relevant enough to be saved. Hauffe thought about integrating personal home pages of researches into the open archive system of a university. Wilma Mossink (SURF Foundation Utrecht, the Netherlands) said that Dutch researchers are at present pressed to submit their publications in institutional repositories.

She presented SURFdiensten, a service system created in Holland for higher education. It offers sort of consortia services to its members: user licences of databases with subscription contracts for several years at a time. According to the need, there are different licences for the same product. The conditions of each licence, however, are the same to all members.

SURF includes yet another service, ICT marketplace which offers digital archiving for higher education institutions and cheap software licences to students.

For ICT and content providers SURFdiensten means one negotiating partner representing the whole education market, simple charging and licensing. For research and education institutions, too, it is a simple one-gate system for obtaining and paying for products with solid legal basis.

\section{Informative product reviews}

There were a couple of product reviews presented in the Conference, linked to the themes of the sessions. Paula McDonnell told about OVID databases and the federated search engine. Very efficient and elegant for health sector, but close to the limits of financial resources of many... She, however, stressed that their system does not have embargoes or archiving restrictions of the material.

Rene Thomas presented the integrated library system Digi Tool 3.0. of Ex Libris. He assured that it represents a new way of thinking: redesigning the repository architecture, setting focus on the object, being more functionary and providing modular and scalable structure. The national library of Austria uses this system, which, I was told later, has proved good but is fairly expensive.

\section{Entering and indexing multilanguage material in a database}

International Atomic Energy Agency (IAEA) has been in the news lately for other reasons than bibliographies. Nevertheless, the presentation of Alexander Nevyjel on indexing the documents entered in the international database INIS was absolutely fascinating even to a person like me who works in a completely different environment.

The indexing is based on the English summaries of all documents. The software carrying out the preliminary indexing is constantly being "taught" to recognize synonyms and various ways of expressing certain physical and chemical substances. Human eyes and brains have to go through and correct all keywords suggested by the software. But thanks to this system documents are now in the database faster than before, the indexing is more coherent and the searching is easier and more accurate.

A Slovenian colleague Aleš Bošnjak from IZUM (Institute of Information Service) presented their database, built for cataloguing researchers. Using this register it is easy to check up-to-date information on a researcher, his/her publications and their "points" indicating the significance of e.g. the journal that has published the article. To be useful, this kind of specialist register needs to be used rather widely, and Bošnjak assured that in addition to Slovenia the database is already used in Serbia-Montenegro, too.

Information for sale - choose how much you want to pay

One of the most interesting presentations came from "real life": Sebastian Crawshaw, Managing Director of OATS, explained how it is possible to make profitable business by selling information that 
is publicly available - but scattered. The clue is to understand what the actual and potential customers need.

It is literally vital for consumers and thus wholesale and retail sellers to know what oils can be used in their particular vehicles. OATS collects information from the lubrication market, oil companies and car manufacturers and sellers. The data is put together and provided in various formats: a database with a few access levels, a web site with extranet and intranet, cd-roms and booklets.

Different customer groups need different products. Crawshaw emphasised the importance of segmentation. His most astonishing message concerned pricing: as people are often ready to pay more for one and the same product for some reason, just let them choose how much they want to pay!

To be successful any organisation must be able to create added value on its products, in this case on information. The idea of OATS is to produce accurate data and to provide their customers an easy access to this information. This means not only user-friendly interfaces but also localisation, including translations into national languages.

When the customers get what they need in an effortless way, the company thrives. In addition to the production work, the basis of success lies on good technical support for customers, appropriate sales and distribution, correct market analyses and good marketing.

This presentation should have shaken university and library folks a little: new approaches to the world of information can create new activities, which are profitable and, moreover, useful to all the parties in the information market in question.

\section{Next year we will meet in Denmark}

During the conference days there was conveniently time for networking, too: good coffee breaks between sessions and two wonderful dinners. Thanks to the organisers, especially to Johan van Halm, who had carried the heaviest load in arranging the meeting and the programme.

The annual meeting decided to continue the work of EUSIDIC though seeking more cooperation with other organisations of the same field and EUSIDIC has received support for the Roskilde Conference from the Danish Research Libraries Association (DF). Next annual conference will be held in Denmark, in the famous rock festival town of Roskilde. The dates, however, are long before the rock'n'roll folks arrive: 11-13 March, 2007. The theme is the impact of Web2.0 and Library2.0 applications on user services for library and information management (www.eusidic.net).

See you next year in Roskilde! And remember to tell your colleagues about this seminar.

Päivi Helander

IPR University Center of the University of Helsinki, and Member of the Board, The Society for Finnish Information Specialists 